\title{
A Social Constructivist Perspective on the Potential Relevance of Selected DSM-5 Disorders for South African Children and Youth
}

\author{
Susan Kriegler \\ Department of Educational Psychology, University of Pretoria, Pretoria, South Africa
}

\begin{abstract}
In South Africa, careless implementation of child psychiatry's biomedical model of 'mental disorder' could stigmatise children and youth who have been made vulnerable by the lingering effects of apartheid - poverty and malnutrition, violence and abuse, and the HIV/AIDS pandemic. A focus on DSM-5 category changes - regarding posttraumatic stress disorder and ADHD - demonstrates that these psychiatric labels are impracticable and irrelevant in a post-colonial developing country where mental health care is delivered in the context of scarce services and unequal access. A social constructivist perspective enables us to broaden policy decisions and suggest directions for research.
\end{abstract}

Keywords: child psychiatry, DSM-5, HIV/AIDS, mental health, poverty, social constructivism, South Africa, stigmatisation, violence

\section{The Social Construction of Mental Illness}

When the American Psychiatric Association (APA) published the updated diagnostic and Statistical Manual of Mental Disorders (APA, 2013), critics of the DSM-5 spotlighted the lowering of diagnostic thresholds for existing disorders and the 
introduction of disorders that may lead to inappropriate medical treatment of vulnerable populations. The storm of protest included concerns about empirical evidence, transparency, field trials, links with the pharmaceutical industry, and, most fundamentally, the biomedical definition of mental disorder. These concerns were grist for the mill within the long history of mental health professionals and sociologists of science challenging DSM and other psychiatric classifications to examine the social and political shaping of categories of 'mental disorder'. For example, Mills (2014) has exposed the creeping psychiatrisation promoted by the Movement for Global Mental Health (MGMH). This movement espouses the lofty agenda of easing the suffering of people in low and middle income countries (LAMIC) by ensuring that these people have access to the best psychiatric drugs. However, Mills (2013a) contends that the failure of a psychiatry dominated by the biomedical model of distress to engage with the social, political and economic contexts that give meaning to distress is a moral failure, particularly in post-colonial societies.

As a paradigm, social constructivism has been highly influential in the deconstruction of psychiatric diagnosis and treatment. If ever a social constructivst approach were needed in service of both a scientific and a social justice agenda, it is in post-colonial developing countries where mental distress emerges from and is shaped by often toxic social interactions, diverse cultural traditions, competing frameworks of knowledge, economic pressures, and unequal power relations. We should be particularly careful in implementing psychiatric diagnostic systems in a country where, in the aftermath of the traumas of apartheid, vast numbers of children and youth are exposed to the cumulative risks associated with poverty and malnutrition, educational disadvantage, violence and abuse, and the Human Immunosuppressive Virus (HIV) / 
Acquired Immunodeficiency Syndrome (AIDS) pandemic. Because psychiatric diagnoses in children, by definition, place the problem squarely within the child, careless implementation of the biomedical model of 'mental disorder' could be one more way of oppressing those who are made vulnerable by the multi-dimensional consequences of early and chronic traumatisation in the aftermath of apartheid. Rabaia, Giacaman and Nguyen-Gillham (2010) argue that Western biomedicalised intervention is inappropriate and ineffective within the historical and political context of loss and injustice, collective exposure to violence, and lack of human security.

The social constructivist approach is rooted in the conceptual distinction between disease (the biological condition) and illness (the social meaning of the condition) (Conrad and Barker, 2010). Thanks to new tools in genetics and neuroimaging, scientists are making progress toward deciphering the underlying biology of emotion and behaviour. However, the genetic and neurobiological foundations of most 'mental diseases,' remain nebulous (Frances and Widinger, 2012). There are no medical tests or reliable biomarkers that would indicate the existence of a physical disease condition at all, and yet this remains the dominant discourse in Western medicine's response to troubled and troubling behaviour. The disease is inferred from social behaviours that deviate from societal expectations (Kinderman and others, 2013). This is all the more questionable if from a scientific point of view the diagnostic system we are using - DSM-5 - is as yet little more than a "rudimentary travel guide to a land we have barely begun to explore" (NHS choices, 2013: 3).

Despite the evidence that drug treatments for psychiatric conditions are nowhere near as effective as is claimed, and the growing evidence that they are harmful, international psychiatry's powerful discourse is an appeal to the moral high ground and 
to social justice (Mills, 2014). It is being exported globally and can influence billions of people's behaviours, impact their subjective experiences, shape their identities, and legitimate psychiatric interventions. However, speaking for South African clinicians, Burns and Alonso-Betancourt (2013: 152) asked, "How many South African or other African psychiatrists took part in the DSM-5 field trials? How do we know whether this system is valid within an African, 'developing country' context?" The psychiatric discourse of mental disorder stands in sharp contrast to traditional African beliefs. In South Africa many people believe that witches or sorcerers can cause mental disorder. A healer or sangoma makes a diagnosis based on divination. Apart from ingestion of herbal powders and animal body parts, treatment is ritualistic and symbolic. A large proportion of people with severe mental disorders utilise both western public healthcare facilities and traditional healing systems concurrently or sequentially (Petersen and Lund, 2011).

A social constructivist perspective enables us to problematise the possible impact of the psychiatric biomedical model on disadvantaged African populations. This Western psychiatric representation thrives on and sustains oppressive power relations (Moncrieff, 2010). Due to their powerless position, children and youth are amongst the most susceptible to psychiatric misdiagnosis and over-diagnosis, and overmedication. LeFrançois (2013a) argues that in psychiatrised children, that is, children categorised with a psychiatric diagnosis, their experiences of childhood may be defined by the diagnosis. However, their status as 'mentally ill' and 'children' may be compounded further by other lived socially disadvantaged subjectivities, such as those based on sexuality, gender, class and racialisation. Psychiatrisation and age - and hence the practice of sanism (Perlin, 2003) and adultism (LeFrançois, 2013a) - are important 
considerations in deconstructing how child psychiatry may denigrate children in research as well as practice, particularly in the context of lingering colonialism (LeFrançois, 2013b).

As troubled and troubling behaviours are increasingly medicalised and pharmacologised in Western societies, international psychiatry expands its diagnostic dragnet to catch the next generation in previously colonised countries. The discourse of 'mental disorder' implies any problem so designated can only be 'cured' by medical practitioners, which misdirects policy and limited resources for more appropriate and effective prevention and treatment (Nelson and Prilleltensky, 2010). The most troubling results of medicalisation is that it encourages medical solutions while ignoring or downplaying the social context of complicated problems, and stigmatises those who are diagnosed as 'mentally ill'.

\section{Psychiatric stigmatisation, sanism, and oppressing the disadvantaged}

Some people find a diagnostic label helpful, but the consequences of stigmatisation include discriminating against the disadvantaged, creating obstacles to education, employment, housing, and social acceptance - particularly in low-income countries (Herman, 2013). The slogan 'depression is a disease like diabetes' does not increase tolerance towards people with mental illness (Angermeyer and others, 2011). Rather, biological attributions make the ill person seem physically distinct - almost a different species. Even worse, genetic attributions can create a halo of stigma for the whole family, who receive new labels such as 'at risk' or 'carrier' (Phelan, 2002).

However, Poole and others (2012) argue that a focus on 'stigma' is still too limiting. Not only does it perpetuate medical conceptions and language around 'mental 
health', but it minimises the reality of widespread rights abuse and oppression experienced by individuals with 'mental health' histories. The term sanism has gained currency in the Mad and psychiatric patient/survivor movements and refers to prejudice that closely parallels racism, sexism, homophobia and ethnic bigotry. Sanism describes the systematic subjugation of people who have received 'mental health' diagnoses or treatment (Perlin, 2003). Like racism, sanism may result in blatant discrimination, but will be most commonly expressed in multiple microaggressions.

Despite one of the most progressive pieces of mental health legislation in the world, South African mental health services is still a tale of inequity and neglect (Burns, 2010), and the human rights of 'mentally ill' persons often are grossly violated (Central Gauteng Mental Health Society, n.d.). Petersen and Lund (2011) reported South African traditional explanatory beliefs promote social isolation of adults diagnosed as mentally ill. We can only guess how labelling affects children in South Africa, but we know from studies conducted in Western societies that in the field of children's mental health care, professional and institutional stigma may produce barriers to care (Heflinger and Hinshaw, 2010), societal rejection (Martin and others, 2007), and lowered educational expectations (Shifrer, 2013).

Despite the global influence of Fanon's (1952) pleas for social justice for marginalized and oppressed people in Africa and elsewhere, neuroethicists (Racine and others, 2005) warn societal appeals to 'hard-wired' differences remain a standard approach by people in positions of power to maintain racial, gender, sexual, and other inequities. The architects of apartheid infamously relied on spurious genetic and neurological racial differences 'proven' by 'mental testing'. The case of South Africa demonstrates that in oppressed communities, transgenerational trauma may be the norm, 
and the trauma extends beyond the progeny of people affected directly (Burstow, 2003).

Abuse and poverty occur everywhere. While acknowledging that the DSM pathologises everyday life difficulties and distress regardless of geographical location, in this article I argue that South African children in particular do not need another wave of false positive epidemics as Western style 'mental illness' expands at its fuzzy border with normality. When mental health care is diagnostically ringfenced, when only those who can afford medical insurance have access to it, and the only form of intervention is pharmacological, the result is under-treatment of the poor and black majority and overtreatment of the affluent minority - thus perpetuating in another form apartheid's harm to both black and white people.

\section{Relevance of DSM diagnoses to South African children and adolescents}

South African prevalence studies are complicated by the use of locally unvalidated diagnostic instruments, yet researchers report alarmingly high figures for psychiatric disorders. For example, Giarelli and others (2009) found $42 \%$ of children in an impoverished rural area screened positive for one or more developmental disabilities. Cortina and others (2013) found teachers identified $41 \%$ of children as having behavioural and emotional problems. More conservatively, Flisher and others (2012) estimated the overall prevalence rate of psychiatric disorders at $17 \%$.

The stark reality is that mental health care is delivered in the context of scarce services and unequal access. Burns (2010) reported there are only 0.28 psychiatrists per 100,000 of the South African population, and 0.32 psychologists. Furthermore, most mental health professionals are located within affluent urban centres, leaving poor urban settlements and rural regions bereft of services. In rural areas and in poor urban 
'townships' state funded mental health services remain limited to emergency management and psychopharmacological care of psychiatric patients (Petersen and others, 2009).

Of South Africa's 48 million citizens, $84 \%$ have no insurance for private mental health services (Board of Healthcare Funders, 2011). Diagnostic 'upcoding' to putatively more severe conditions occurs for reimbursement purposes. The percentage of Bipolar Disorder (BPD) diagnoses in private healthcare showed a staggering increase of $228 \%$ between 2006 and 2011 (Child, 2013). Significantly, BPD is one of only two 'psychiatric diseases' for which all treatment costs must by law be paid by medical aid schemes (the other is schizophrenia). Thus the irony is that the majority of those children and youth in South Africa who are potentially labelled are merely represented in epidemiological statistics but may never receive help. The question in light of the oppressive nature of biomedical psychiatry is whether there should be more of it. Should every child have the right to a psychotropic childhood? (Mills, 2014).

\section{Risks affecting the mental well being of South African children and adolescents}

The wider context within which this question should be answered is an African continent shattered by political, economic, and cultural problems that are, at least in part, the heritage of centuries of colonial exploitation. Burstow (2003) observes that just as individual members of oppressed groups are traumatized by systemic oppression, communities themselves are also traumatized. Post-colonial and post-apartheid South African society bears witness to the significance of group trauma, community trauma, and historical trauma. There is a need to critically assess the utility of using diagnostic 
categories to pathologise what should be seen as problems arising from oppression, poverty, abuse and violence, and the AIDS pandemic.

\section{Poverty and malnutrition}

The most visible legacy of apartheid's social and economic oppression of the black majority is the lingering unequal distribution of income that still prevents large sections of the population from sharing in the benefits of economic growth. Many poor black children experience chronic hunger (Armstrong and others, n.d.). Laing (2012) reported more than half of our children live in poverty; 1.7 million live in shacks, with no proper bedding, cooking or washing facilities. Health risks associated with pervasive poverty and malnutrition result in cognitive or sensory impairments (Ampaabeng and Ming, 2012). Chronic protein energy malnutrition (stunting) affects the ongoing development of higher cognitive processes (Kar and others, 2008). However, a variety of other factors related to child nurturing and stimulation under conditions of poverty interact with and reinforce one another to impede cognitive development (Richter and others, 2009). Where cognitive development is blighted, failure to acquire basic literacy and numeracy reflects the reproduction of disadvantage (Donald and others, 2010). With around $27 \%$ of public schools lacking basic amenities such as running water (UNICEF, 2013), many children experience a broken journey through school, interrupted by irregular attendance, absent teachers, teenage pregnancy, falling prey to drug abuse, and school-related abuse and violence. 


\section{Violence and abuse}

It is not surprising that exposure to violence in schools, the community, and the home is associated with Post Traumatic Stress Disorder (PTSD) (Fowler and others, 2009), but Burstow (2003) argues that such trauma may transgenerationally affect whole communities. Indeed, South Africa's levels of exposure to violence, maltreatment, abuse, neglect and exploitation of children are among the highest in the world (Dawes and others, 2005). According to Flisher and others (2012), although the real figure can only be guessed, there are more than 54,000 reported crimes against children annually. Sexual abuse makes up about half the figure. Around $30 \%$ of victims are under 10 years old. Much of the sexual violence occurs in schools; almost a quarter of 10-12 year old rural children feel unsafe in school (Cortina and others, 2013). In a society where sexual abuse of girls is rampant, gender blind mental disorder statistics may disguise the extent of traumatisation in a group where age and gender may intersect to reproduce them as particular targets for violence and oppression. Perpetrators are shielded by the traditionally low status of girls and a socio-cultural view that sexual abuse is a private matter. One result is the rising tide of teen pregnancies. One in three girls has had a baby by the age of 20 , and $16 \%$ of them are infected by HIV/AIDS (IRIN, 2007).

\section{The HIV/AIDS pandemic}

In 2008 the HIV prevalence among South Africans was 16.9\%. The prevalence among children aged 2-14 was 2.5\%, and 40\% die from the pandemic annually (Laing, 2012). Much like leprosy in previous times, HIV/AIDS has a powerful stigma and illustrates the disconnection from community and others that is inherent in trauma (Burstow, 2003). It can make people less likely to seek treatment for fear of being mistreated by 
health care providers and publicly associated with a tainted condition. Orphans, and children affected by maternal HIV/AIDS, are especially vulnerable to violence, abuse, neglect, and exploitation (King and others, 2009). Both infected and uninfected children of HIV-positive mothers show delays in language and brain development (Rochat and Hough, 2007). Long-term consequences are poor educational outcomes, high rates of intergenerational poverty, and the continued cycle of women's disempowerment. HIV/AIDS in children result in cognitive impairment, developmental delay, attention problems, 'serious mental illness', and 'common mental disorders', including depression, anxiety, and substance abuse (Flisher and others, 2012). Not only these afflicted children and adolescents, but also many others may potentially be affected by DSM-5 changes in psychiatric diagnoses.

\section{Implications for South Africa of DSM-5 child and adolescent disorders}

While the MGMH seeks to export psychotropic drugs for children to the global South, research in the global North has found that the long-term use of these drugs may be at best ineffective, or at worst harmful (Mills, 2014). During the past two decades, child psychiatry has already provoked three international fads - a tripling of ADHD, a more than 20-times increase in Autistic Disorder, and a 40-times increase in childhood BPD (Frances, 2012). Increased PTSD and ADHD diagnoses are two of the 'potential disasters' for South African children and youth resulting from DSM-5 changes.

\section{Post-Traumatic Stress Disorder}

We may hope DSM-5's increased recognition of disorders due to abuse and neglect in childhood, including introduction of a PTSD subtype for preschool children, will 
foreground trauma associated with childhood adversities. Many South African children experience the maladaptive, long-lasting, and multi-dimensional consequence of chronic, early, and developmental traumatisation that Sar (2011) contended is the essence of Complex PTSD. However, as Burstow (2003) points out, trauma is a not a disorder but a reaction to a kind of wound. Moreover, the diagnosis individualises social problems and pathologizes traumatized people. PTSD is a grab bag of contextless symptoms, divorced from the complexities of people's lives and the social structures that give rise to them.

Symptoms of trauma are polymorphous and may include being easily irritated and angered, which may be confused with an entirely new condition added in the DSM5: Disruptive Mood Dysregulation Disorder (DMDD). This expansion of psychiatry's diagnostic dragnet by pathologizing anger in children is intended to address overdiagnosis of paediatric BPD (Frances, 2012). The obvious solution was not to introduce DMDD but to tighten the criteria for BPD. The changing landscape of childhood disorders illustrates Burstow's (2003) argument that mental disorders are a function of the power of psychiatry. Moreover, by psychiatrising their experience, we not only violate the person, but also increase the possibility of the person being subjected to more substantial psychiatric interference in future. Diagnoses are an entry point to more intrusive and inherently traumatising measures such as incarceration, drugging, and electroshock.

Overall, the symptoms of PTSD, DMDD, and BPD may occur in conjunction with a bouquet of 'comorbid childhood disorders', including Oppositional Defiant Disorder (ODD), and / or Conduct Disorder, Anxiety Disorders, Obsessive Compulsive 
Disorder (OCD), Depressive Disorders, Autism Spectrum Disorders, and ADHD (Copeland and others, 2013).

\section{Attention Deficit/Hyperactivity Disorder}

The more lenient DSM-5 requirements make it difficult to imagine how the rate of ADHD diagnoses will not increase. The British Psychological Society (BPS) (2012) expressed concern about the differential diagnosis rates for ADHD between countries. In defence of emphasising the 'fairly uniform prevalence' of ADHD across cultures, DSM-5 ADHD work group members - Polanczyk and Rohde (2007) - said they wanted to confirm the 'reality of the disorder' because they aspired to get treatment to poor children.

ADHD is a label for heterogeneous collections of dimensional behaviours that have heterogeneous causes (Parens and Johnston, 2008). There is an inevitable zone of ambiguity, but because DSM is so important for reimbursement, users often adopt its language while ignoring its limitations. Breggin (2014) addresses the scientific and moral question of whether it is ever in the best interests of a child to be given a psychiatric drug, and Mills (2013b) asks why, if the drugs used to treat ADHD are chemically the same as speed and cocaine, we do not react with horror to the idea that such drugs as Ritalin are given to children by doctors. While ADHD is over-diagnosed in affluent communities, perhaps fortunately, a significant proportion of lower socioeconomic status children with ADHD do not receive stimulants. Pertinent to the South African context, Reading (2013) reported there is a strong relationship between poverty, maltreatment, and ADHD. 
Bakare (2012) reviewed four South African studies that documented a prevalence of about $5 \%$. However, ADHD prevalence is between $45.5 \%$ to $100.0 \%$ amongst children with possible organic brain pathology, particularly HIV infection, tuberculosis meningitis, intellectual disability, and toxic or physical insults. A question is whether a diagnosis of ADHD in these children is at all appropriate. Validity issues need to be addressed in specific socio-cultural contexts to avoid imposing a diagnostic category on another culture where it lacks coherence (Rousseau and others, 2008). Once again, the challenges of assessment are due to the large number of comorbidities, including Specific Learning Disorder (SLD).

Regarding SLD, the South African reality is that we simply do not have the resources to meet the requirement that a DSM-5 SLD diagnosis should be confirmed by individually administered standardized achievement measures and comprehensive clinical assessment. Many have lauded the Department of Education (2005) for its vision of inclusive education that moves away from the medical model and shifts instead towards locating barriers to learning in system deficiencies, social problems, and poverty. Sadly, the Department has a dismal track record in providing even the basics in education for the majority of South African children.

\section{Discussion}

An ongoing challenge has been to find a balance between concerns related to the stigmatisation of 'mental disorders' and the need for diagnostic categories that facilitate access to healthcare. However, for behavioural outcomes to be labelled as such they must in fact be disorders or illnesses, and not caused by inadequate support and resources. Responding to psychological distress through a psychiatric discourse where 
the child is the locus for change fails to address how suffering can arise through exposure to pernicious political and economic ideologies. Promoting psychiatric or pharmacological interventions devalues Indigenous knowledge systems, ignores cultural specificity and contributes to new forms of colonialism through a globalisation discourse.

We certainly do not need another wave of false positive epidemics as Western style 'mental illness' marches forward, expanding psychiatric diagnosis at its fuzzy border with normality. South African children and youth bear witness to the significance of group trauma, community trauma, and historical trauma. The increased recognition of trauma- and stressor-related disorders that foregrounds abuse and neglect in childhood is welcome, but invoking the concept of 'disorder' undermines a humane response by implying that these experiences indicate an underlying defect.

Moreover, the high rate of 'comorbidity' suggests that most of these 'disorders' are labels for heterogeneous collections of dimensional behaviours that have heterogeneous causes, each haloed by an expanding zone of fuzziness as diagnostic thresholds are lowered. For developing countries, resource limitations and lack of appropriate assessment tools may render the growing complexity of comorbidity impracticable, if not irrelevant. In ethnically and linguistically diverse nations, survey findings using ethnocentrically Western instruments and diagnoses may be uninterpretable, yet may misdirect policy and treatment. Upcoding occurs when the only form of intervention that is reimbursed is pharmacological, and such treatment is diagnostically yoked, which in turn contributes to reification of disorders, distorts epidemiological data, and spawns research based on pseudo-categories. The problem of under-treatment applies to the poor and black majority, while overtreatment applies to 
the affluent minority.

\section{Recommendations}

We must avoid the trap of overreaction to the problem of overtreatment in tackling the problem of under-treatment. The boundary for receiving help in the face of risk and distress should not be guarded by a diagnostic manual. Rather than being additionally burdened with psychiatric labels, children and youth need inexpensive psycho-educational interventions, particularly within school-based, primary care and resilience-focused prevention efforts. Although ‘community' may become another euphemism for black and disadvantaged, we need to explore the utility of different forms of critical and community psychology that avoid marginalising Indigenous knowledge systems. Interventions should be contextually appropriate, should empower existing social support systems, and strengthen social cohesion and self-help within communities.

In a society where inequity lingers, policymakers and researchers should ask searching questions about the interaction between children and their emotional, cultural, economic, political and social ecologies. This does not mean we should abandon entirely the idea of distinctive psychiatric syndromes, nor does it mean we should adopt a concept of global risk. Explanatory models and research should include the concepts of equifinality and multifinality, and address the interplay of socioeconomic and environmental stressors.

We are far from solving the conflict between a more universalist vision of psychopathology and a relativist one. Therefore, classification systems need to be constructed and implemented in a flexible way. There are far too many diagnoses, so 
the overall number of diagnoses should be drastically reduced and the requirement of impairment should be removed from all diagnoses. An ideal approach should include a spectrum model of mental health that incorporates graded, evidence-based interventions delivered by a range of providers at each point along its continuum.

In seeking to understand human experience of adversity as pathways of risk and resilience, we need to ask complex questions, such as when, how, why and for whom resources truly matter. Policy-relevant research should use approaches that encourage participation of community members, and strategies for empowering people. An assetbased, multisystem approach within a human rights paradigm is required to enable full engagement by people with psychosocial distress, including their involvement in policy development. More researchers should embrace a critical or anti-oppressive stance. Retheorising should recognize how the predominant use of the medical model has pushed other approaches to the periphery, such as anti-oppressive practice (AOP), intersectionality, and the social model of disability (Poole et al., 2012). Researchers should target the presence and impact of sanism and adultism, and the potential oppression of psychiatrised children and youth in post-colonial and racialised societies.

\section{Conclusion}

The increased psychiatrisation advocated by the MGMH to ease the suffering in LAMICs is based on a lofty agenda, but imposes a stigmatized identity on people and imposes possibly harmful treatments on them. In resource-constrained countries, we need to think carefully about implementing DSM-5 modifications that risk increasing diagnostic inflation and comorbid obfuscation, suggest an ecologically blind neurobiological aetiology, and imply only biomedical treatment modalities. We need to 
be all the more cautious if the consequences of psychiatric labelling offer little hope of access to mental health care, and risk increasing discrimination against those who are already disadvantaged, while obviating the need for culturally appropriate and resilience-focused interventions. We should question the normalising connections between psychiatrisation, colonialism, racialisation, and adultism and deconstruct how the making and meaning of diagnostic categories contributes to wider social and clinical debates that emerge from and recreate social, political and economic conditions.

\section{REFERENCES}

American Psychiatric Association (APA). 2013. Diagnostic and statistical manual of mental disorders (5th ed.). Arlington, VA: American Psychiatric Publishing.

Ampaabeng SK, Ming C. 2012. The long-term cognitive consequences of early childhood malnutrition: The case of famine in Ghana. http://www.dartmouth.edu/ neudc2012/docs/paper_323.pdf [accessed 12 December 2013].

Angermeyer MC, Holzinger A, Carta MG, Schomerus G. 2011. Biogenetic explanations and public acceptance of mental illness: Systematic review of population studies. British Journal of Psychiatry 199(5): 367-372. DOI: 10.1192/bjp.bp.110.085563

Armstrong P, Lekezwa B, Siebritz K. n.d. Poverty in South Africa: A profile based on recent household surveys. Stellenbosch Economic Working Papers: 04/08. Stellenbosch: Bureau for Economic Research, University of Stellenbosch.

Bakare MO. 2012. Attention deficit hyperactivity symptoms and disorder (ADHD) among African children: A review of epidemiology and co-morbidities. African Journal of Psychiatry 15(5): 358-361. DOI: http://dx.doi.org/10.4314/ajpsy.v15i5.45.

Board of Healthcare Funders. 2011. 84\% of South Africans have no medical aid cover. BusinessLIVE, 29 June. http://www.bhfglobal.com/84-south-africans-have-no-medical-aid-cover-290611 [accessed 12 December 2013].

Breggin PR. 2014. The rights of children and parents in regard to children receiving psychiatric diagnoses 
and drugs. Children \& Society 28(3): 231-241. DOI: 10.1111/chso.12049

British Psychological Society (BPS). 2012. Socioeconomic status and ADHD in children.

http://www.bps.org.uk/news/socioeconomic-status-and-adhd-children [accessed 12 December 2013].

Burns JK. 2010. Mental health services funding and development in KwaZulu-Natal: a tale of inequity and neglect. South African medical journal 100(10): 662-666.

Burns JK, Alonso-Betancourt O. 2013. Are we slaves to DSM? A South African perspective. African Journal of Psychiatry 16(3): 151-155. http://dx.doi.org/10.4314/ajpsy.v16i3.18.

Burstow B. 2003. Toward a radical understanding of trauma and trauma work. Violence Against Women 9(11): $1293-1317$. DOI: $10.1177 / 1077801203255555$

Central Gauteng Mental Health Society. (n.d.). Who is Central Gauteng Mental Health Society? http://www.cgmhs.co.za [accessed 12 December 2013].

Child K. 2013. Bipolar disorder cases show 'staggering increase'. Times Live, 5 September. http://www.timeslive.co.za/thetimes/2013/09/05/bipolar-disorder-cases-show-staggeringincrease [accessed 12 December 2013].

Conrad P, Barker KK. 2010. The social construction of illness: Key insights and policy implications. Journal of Health and Social Behavior 51(1): S67-S79. DOI: 10.1177/0022146510383495

Copeland WE, Angold A, Costello EJ, Egger H. 2013. Prevalence, comorbidity, and correlates of DSM-5 proposed Disruptive Mood Dysregulation Disorder. American Journal of Psychiatry 170(2): 173-179. DOI: 10.1176/appi.ajp.2012.12010132.

Cortina MA, Fazel M, Hlungwani TM, Kahn K, Tollman S, Cortina-Borja M, Stein A. 2013. Childhood psychological problems in school settings in rural Southern Africa. PLoS One 8(6): e65041. DOI: 10.1371/journal.pone.0065041

Dawes A, De Sas Kropiwnicki Z, Kafaar Z, Richter L. 2005. Corporal punishment of children: A South African national survey. Paper prepared for distribution at the regional consultation of the United Nations study on violence against children. Sweden: Save the Children. http://www.rapcan.org.za/cp_docs/3456_Dawes_corporalpunishmentofchildren.pdf [accessed 12 December 2013]. 
Department of Education. 2005. Conceptual and operational guidelines for the implementation of inclusive education: Special schools as resource centres. http://www.education.gov.za/LinkClick.aspx?fileticket=wHOV71RtQ1A= [accessed 12 December 2013].

Donald D, Lazarus S, Lolwana P. 2010. Educational psychology in social context: Ecosystemic applications in Southern Africa (4 ${ }^{\text {th }}$ ed). Cape Town, SA: Oxford University Press.

Fanon FO. 1952. Black skin, white masks (1967 translation by Charles Lam Markmann). New York: Grove Press.

Flisher AJ, Dawes A, Kafaar Z, Lund C, Sorsdahl K, Myers B, Thom R, Seedat S. 2012. Child and adolescent mental health in South Africa. Journal of Child \& Adolescent Mental Health 24(2): 149-161. DOI: $10.2989 / 17280583.2012 .735505$

Fowler PJ, Tompsett CJ, Braciszewski JM, Jacques-Tuira AJ, Baltes BB. 2009. Community violence: A meta-analysis on the effect of exposure and mental health outcomes of children and adolescents. Developmental and Psychopathology 21(1): 227-259. DOI: 10.1017/S0954579409000145.

Frances A. 2012. DSM-5 is a guide, not a bible - simply ignore its 10 worst changes. Psychiatric Times. http://www.psychiatrictimes.com/blogs/dsm-5/dsm-5-guide-not-bible\%E2\%80\%94simplyignore-its-10-worst-changes [accessed 11 December 2013].

Frances AJ, Widinger T. 2012. Psychiatric diagnosis: Lessons from the DSM-IV past and cautions for the DSM-5 future. Annual Review of Clinical Psychology 8: 109-130. DOI: 10.1146/annurevclinpsy-032511-143102

Giarelli E, Clarke DL, Catching C, Ratcliffe SJ. 2009. Developmental disabilities and behavioral problems among school children in the Western Cape of South Africa. Research in Developmental Disabilities 30(6): 1297-1305. DOI: 10.1016/j.ridd.2009.05.006.

Heflinger CA, Hinshaw SP. 2010. Stigma in child and adolescent mental health services research: understanding professional and institutional stigmatization of youth with mental health problems and their families. Administration and Policy in Mental Health 37(1-2): 61-70. DOI: 10.1007/s10488-010-0294-Z.

Herman H. 2013. Reflections on psychiatry and international mental health. Mens Sana Monographs 11(1): 59-67. DOI: 10.4103/0973-1229.104485. 
IRIN. 2007. South Africa: Teenage pregnancy figures cause alarm. http://www.irinnews.org/report/70538/ [accessed 12 December 2013].

Kar BR, Rao SL, Chandramouli BA. 2008. Cognitive development in children with chronic protein energy malnutrition. Behavioral and Brain Functions 4: 31. DOI: 10.1186/1744-9081-4-31

Kinderman P, Read J, Moncrieff J, Bentall RP. 2013. Drop the language of disorder. Evidence Based Mental Health 16: 2-3. DOI: 10.1136/eb-2012-100987

King E, De Silva M, Stein A, Patel V. 2009. Interventions for improving the psychosocial well-being of children affected by HIV and AIDS. The Cochrane Database of Systematic Reviews 15(2): CD006733. DOI: 10.1002/14651858.CD006733.pub2.

Laing A. 2012. More than half of South Africa's children live in poverty. The Telegraph. http://www.telegraph.co.uk/health/healthnews/9280481/More-than-half-of-South-Africaschildren-live-in-poverty.html [accessed 12 December 2013].

LeFrançois BA. 2013a. Queering child and adolescent mental health services: The subversion of heteronormativity in practice. Children \& Society 27: 1-12. DOI: 10.1111/j.1099$\underline{0860.2011 .00371 . x}$

LeFrançois BA. 2013b. The psychiatrization of our children, or, an autoethnographic narrative of perpetuating First Nations genocide through 'benevolent' institutions. Colonization Indigeneity, Education \& Society 2(1): 108-123.

http://decolonization.org/index.php/des/article/viewFile/18687/16239 [accessed 12 June 2014].

Martin JK, Pescosolido BA, Olafsdottir S, Mcleod JD. 2007. The construction of fear: Americans' preferences for social distance from children and adolescents with mental health problems. Journal of Health and Social Behavior 48(1): 50-67. DOI: 10.1177/002214650704800104

Mills C. 2013a. Decolonizing Global Mental Health: The Psychiatrization of the Majority World. London: Routledge.

Mills C. 2013b. Violent 'treatment': Who counts as a child and what counts as violence? Seminar; Aesthetics, ethics, politics: representations of violence against children. http://oxford.academia.edu/ChinaMills [accessed 12 June 2014].

Mills C. 2014. Psychotropic childhoods: Global mental health and pharmaceutical children. Children \& Society 28(3): 194-204. DOI: 10.1111/chso.12062 
Moncrieff J. 2010. Psychiatric diagnosis as a political device. Social Theory \& Health 8(4): 370-382.

DOI: $10.1057 /$ sth.2009.11

Nelson G, Prilleltensky I. (eds). 2010. Community Psychology: In pursuit of liberation and well-being ( $2^{\text {nd }}$ ed.). New York: Palgrave Macmillan.

NHS choices. 2013. Controversy over DSM-5: New mental health guide. http://www.nhs.uk/news/2013/08August/Pages/controversy-mental-health-diagnosis-andtreatment-dsm5.aspx [accessed 12 December 2013].

Parens E, Johnston J. 2008. Facts, values, and Attention-Deficit Hyperactivity Disorder (ADHD): An update on the controversies. Child and Adolescent Psychiatry and Mental Health 3(1): 1-33. DOI: $10.1186 / 1753-2000-3-1$

Perlin M. 2003. You have discussed lepers and crooks: Sanism in clinical teaching. Clinical Law Review 9: $683-729$.

Petersen I, Bhana A, Campbell-Hall V, Mjadu S, Lund C, Kleintjies S, Hosegood V, Flisher AJ, Mental Health and Poverty Research Programme Consortium. 2009. Planning for district mental health services in South Africa: a situational analysis of a rural district site. Health Policy and Planning 24(2): 140-150. DOI: 10.1093/heapol/czn049

Petersen I, Lund C. 2011. Mental health service delivery in South Africa from 2000 to 2010: One step forward, one step back. The South African Medical Journal 101(10). http://www.samj.org.za/index.php/samj/article/view/4841/3584 [accessed 13 December 2013].

Phelan JC. 2002. Genetic bases of mental illness - a cure for stigma? Trends in Neurosciences 25(8): 430-431. http://dx.doi.org/10.1016/S0166-2236(02)02209-9

Polanczyk G, Rohde LA. 2007. Drs. Polanczyk and Rohde reply. American Journal of Psychiatry 164: 1612-1613. DOI: 10.1176/appi.ajp.2007.07060942r.

Poole JM, Jivraj T, Arslanian A, Bellows K, Chiasson S, Hakimy H, Pasini J, Reid J. 2012. Sanism, 'mental health', and social work/education: A review and call to action. Intersectionalities: A Global Journal of Social Work Analysis, Research, Polity, and Practice 1: 20-36. http://journals.library.mun.ca/ojs/index.php/IJ/article/view/348/227 [accessed 12 June 2014]. 
Rabaia Y, Giacaman R, Nguyen-Gillham V. 2010. Violence and adolescent mental health in the occoupied Palestinian territory: A contextual approach. Asia-Pacific Journal of Public Health 22(3): 2164-2215. DOI: 10.1177/1010539510373028

Racine E, Barr-Ilan O, Illes J. 2005. fMRI in the public eye. Nature Reviews Neuroscience 6(2): 159-164. DOI: $10.1038 / \mathrm{nrn} 1609$

Reading R. 2013. Poverty, maltreatment and attention deficit hyperactivity disorder By E. Webb (2013) Archives of Disease in Childhood, 98, 397-400. Child: Care, Health and Development 39(5): 762-763. DOI: 10.1111/cch.12096_2

Richter L, Stein A, Cluver L, De Kadt J. 2009. Infants and young children affected by HIV/AIDS. In HIV/AIDS in South Africa 25 years on: Psychosocial perspectives. Rohleder P, Swartz I, Kalichman SC, Simbayi LC (eds). Springer: New York; 69-88/

Rochat T, Hough A. 2007. Enhancing resilience in children affected by HIV/AIDS: Children's views and experiences of resilience enhancing family and community practices. Human Sciences Research Council. http://www.crin.org/docs/Children\%20and\%20Resilience\%20Final.pdf [accessed 13 December 2013].

Rousseau C, Measham T, Bathiche-Suidan M. 2008. DSM IV, culture, and child psychiatry. Journal of the Canadian Academy of Child and Adolescent Psychiatry 17(2): 69-75. http://www.ncbi.nlm.nih.gov/pmc/articles/PMC2387108/pdf/0170069.pdf [accessed 13 December 2013].

Sar V. 2011. Developmental trauma, complex PTSD, and the current proposal of DSM-5. European Journal of Psycho-Traumatology 2. http://www.ejpt.net/index.php/ejpt/article/view/5622/html_100 [accessed 13 December 2013].

Shifrer D. 2013. Stigma of a label: Educational expectations for high school students labeled with learning disabilities. Journal of Health and Social Behavior 54(4): 462-480. DOI: $10.1177 / 0022146513503346$

UNICEF. 2013. UNICEF South Africa: Annual Report 2012. Pretoria: UNICEF. http://www.unicef.org/southafrica/SAF_resources_annual2012.pdf [accessed 17 December 2013]. 